\title{
DOE/PC/93220-.T8
}

Quarterly Technical Progress Report

October 1, 1995 - December 31, 1995

\author{
DOE Report No.: \\ DE-PS22-93PC93201-9
}

Project Title:
Production of Elemental Sulfur and Methane from $\mathrm{H}_{2} \mathrm{~S}$ and $\mathrm{CO}_{2}$
Derived from a Coal Desulfurization Process
DE- FG22- 93PC 93220
by

Sung-Yong Gong, Xueyu Jiang and Soon-Jai Khang (PI)

Department of Chemical Engineering

Timothy C. Keener (Co-PI)

Department of Civil and Environmental Engineering

University of Cincinnati

Cincinnati, OH 45221-0171

(513)556-2789

\begin{abstract}
During the ninth quarter of the project, bench scale experiments were performed to investigate the adsorption ability of different kinds of materials within sulfur vapor environment. Four kinds of adsorbents have been tested. The experiment results indicated that activated carbon was the best of four adsorbents tested. The adsorption process may be applicable to promote conversion of $\mathrm{H}_{2} \mathrm{~S}$ in the $\mathrm{H}_{2} \mathrm{~S}$ and $\mathrm{CO}_{2}$ reaction system.
\end{abstract}

"U.S./DOE Patent Clearance is not required prior to publication of this document." 


\section{Work Performed}

\section{Experimental Apparatus for Adsorption of Sulfur Vapor}

The experimental apparatus for adsorption of sulfur is schematically shown in Figure 1. Elemental sulfur is loaded in a Pyrex glass tube which is 1 inch in I.D. and 10 inches in length. Total amount of sulfur is approximately 30 grams. Oxygen free nitrogen is used to purge the inside of the glass tube to maintain an inert environment. The flowrate is controlled by a rotameter. The adsorbents are loaded into a small basket made of stainless steel screen. The amount of adsorbent used in the each run is around $400-500 \mathrm{mg}$. The Pyrex glass tube, containing the adsorbent basket and sulfur, is heated by a tubular furnace to reach the expected experimental temperatures. Two K-type thermocouples are used in the system. One measures the temperature of the adsorbent basket, the other is connected to the tubular furnace which monitors the upper temperature limit.

\section{Chemicals Used in the Investigation}

The adsorbents for this period of research were obtained from commercial sources. The adsorbent tested were $\mathrm{Al}_{2} \mathrm{O}_{3}$ (two kinds of shape), CoO- $\mathrm{MoO}_{3}$-Alumina and activated carbon. Oxygen free nitrogen was purchased from Wright Brothers Inc., a distributor for the Matheson Gas Products. Sublimed sulfur powder was obtained from Fisher Scientific Inc. Cobalt-molybdenum (CoO- $\mathrm{MoO}_{3}$-Alumina, Crosfield 465, 1/20" extruded) was obtained from Crosfield Catalysts (4099 West 71st Street, Chicago, Illinois 60629). The aluminum oxide was purchased from Engelhard Corporation (120 Pine Street, Elyria, Ohio 44035). The 
activated carbon (mesh 12 x 40) was obtained from Autochem North America (Mineral Products Division, Three Parkway, Philadelphia, PA 19102).

\section{Experimental Condition and Procedure}

Figure 2 shows the relationship of sulfur vapor pressure with temperature at $1 \mathrm{~atm}$ from three independent sources (Perry et al, 1984, Hultgren et al, 1973 and Barin et al, 1977). Due to the different research interests of the investigators, the sulfur vapor pressure data in these sources do not cover the same temperature range. However, they are consistent with each other in their tendencies and overlap areas within the temperature range of our interest and are accurate enough for the present purpose. Figure 2 shows that sulfur vapor pressure increases exponentially with the temperature. This feature makes the operation temperature of condensed sulfur very sensitive to the efficiency of sulfur removal from vapor phase. In order to experimentally investigate the effect of the different kinds of materials on sulfur vapor condensation and adsorption, the following experimental procedure was performed during the tests.

(1) Load sulfur into the Pyrex glass tube.

(2) Purge the tube with oxygen free nitrogen to make an inert environment.

(3) Raise the furnace temperature to $150^{\circ} \mathrm{C}$. This step was necessary to minimize the initial condensation of sulfur vapor on adsorbent surface. It might occur when there is a temperature difference between the hot glass tube and adsorbent basket containing the adsorbents which were dried and kept in the oven at $150^{\circ} \mathrm{C}$. 
(4) Load the adsorbent of $400-500 \mathrm{mg}$ on to a small basket made of stainless steel screen. Insert the basket into the tube.

(5) Then raise the furnace temperature to a desired experimental value.

(6) Stop purging of oxygen free $\mathrm{N}_{2}$ when the desired temperature is reached.

(7) After a predetermined duration of time, take out the basket and measure the weight change of the adsorbent.

\section{Result and Discussion}

The results of the experiment are shown in Tables 1 and 2 . There were four kinds of adsorbents tested during the investigation. They were $\mathrm{Al}_{2} \mathrm{O}_{3}$ (with two different shapes), $\mathrm{CoO}-\mathrm{MoO}_{3}$-Alumina and activated carbon.

Table 1. Amount of Sulfur Adsorbed (wt \% of adsorbent), Temperature was Maintained at $290 \pm 5^{\circ} \mathrm{C}$

\begin{tabular}{|c|c|c|c|c|}
\hline $\begin{array}{c}\text { Temp } \\
\text { (hours) }\end{array}$ & Activated & $\begin{array}{c}\text { Co- } \mathrm{Mo}_{-} \mathrm{Al}_{2} \mathrm{O}_{3} \\
\text { (extruded) }\end{array}$ & $\begin{array}{c}\mathrm{Al}_{2} \mathrm{O}_{3} \\
\text { (sphere type) }\end{array}$ & $\begin{array}{c}\mathrm{Al}_{2} \mathrm{O}_{3} \\
\text { (cylinder type) }\end{array}$ \\
\hline 0.17 & 4.3 & - & - & - \\
\hline 0.5 & 20.1 & 0.0 & 0.0 & 2.6 \\
\hline 1.0 & 43.9 & 0.0 & 0.0 & 2.8 \\
\hline 2.0 & 47.2 & 3.3 & 0.0 & 6.3 \\
\hline 3.0 & 52.9 & 5.4 & 12.3 & 5.0 \\
\hline 5.0 & 70.8 & 2.6 & 11.7 & 6.1 \\
\hline
\end{tabular}




\begin{tabular}{|c|c|c|c|c|}
\hline 5.0 & - & 3.2 & - & - \\
\hline 8.0 & 74.2 & 28.9 & 12.5 & 8.7 \\
\hline
\end{tabular}

Table 2. Amount of Sulfur Adsorbed (wt $\%$ of adsorbents), Temperature was Maintained at $220 \pm 5^{\circ} \mathrm{C}$

\begin{tabular}{|c|c|}
\hline Temp (hours) & Activated Carbon \\
\hline 5.0 & 8.9 \\
\hline 8.0 & 23.6 \\
\hline
\end{tabular}

The experimental results are also plotted in Figure 3. It indicates that activated carbon was the best adsorbents among the four adsorbents tested. The amount of sulfur adsorbed on the activated carbon increased with the experimental time and did not reach an equilibrium value. Capillary condensation occurring in the pores may be responsible for this behavior. In the case of $\mathrm{Al}_{2} \mathrm{O}_{3}$ (both sphere and cylinder types), adsorption of sulfur almost remained constant for 3 hours. At higher temperature, above $420^{\circ} \mathrm{C}$, oxidation of activated carbon was observed because of possible existence of a little amount of oxygen in the tube even though the purge step was performed prior to the experiment. During the same period of experimental time, the amount of sulfur adsorbed on activated carbon at lower temperature (e.g. $220^{\circ} \mathrm{C}$ ) were smaller than that of at high temperature (e.g. $290^{\circ} \mathrm{C}$ ). It is due to the fact that the lower the system temperature, the less vaporized sulfur ${ }^{[2-4]}$ is available for adsorption (low partial pressure of sulfur). However, the results of the experiment do prove that adsorption process is possible to remove sulfur vapor from gas mixtures, such as $\mathrm{H}_{2} \mathrm{~S}$ and 
$\mathrm{CO}_{2}$ reaction system, and promote the conversion of $\mathrm{H}_{2} \mathrm{~S}$. The present experimental apparatus is not equipped to control the sulfur vapor mole fraction quantitatively with respect to the experimental temperature. It did not provide a perfect inert (oxygen free) circumstance for the investigation either. Therefore, some improvement on the experiment system is necessary for the further investigations.

\section{New Apparatus}

The new design is shown schematically in Figure 4. The system consists of two sulfur vaporizer, three temperature controllers and an adsorption bed. The vaporizers are made of stainless steel with the dimension of 2.5 inches in O.D. and 7 inches in height. The connection tubings are all made of $1 / 4$ inch stainless steel tubes. The temperature controllers (Omega, $\mathrm{CN}$ 9000A), K-type thermocouples (O.D. 1/16") were obtained from the Omega Technologies Company (One Omega Drive, Box 4047, Stamford, Connecticut 06907). And flexible electric heating tapes (AWH-051-060DSP) were purchased from Amptek Company (P.O. Box 1381, Stafford, Texas 77497). During the experiment, the temperature in the first sulfur vaporizer will always be higher than the second one in order to generate saturated sulfur vapor. The saturated sulfur vapor pressure produced by the system is based on the relationship between sulfur vapor pressure and temperature diagram shown in Figure 2.

\section{Future Work}

The new apparatus for sulfur vapor adsorption will be used to further investigate 
condensation and adsorption effect of sulfur vapor on activated carbon at higher temperatures. The old apparatus could not control the sulfur vapor pressure effectively. The new apparatus will extend the range of experimental temperature and help to find out at which temperature sulfur vapor can be mostly and effectively condensed or adsorbed by activated carbon.

In view of the possible sulfur removal, the catalytic reaction of $\mathrm{H}_{2} \mathrm{~S}$ and $\mathrm{CO}_{2}$ will be carried out in a wider range of temperature to find out the optimum operating condition for the process.

\section{References}

[1] Yang, Ralph T., Gas Separation by Adsorption Processes. Butterworth Publishers, Boston (1987).

[2] Perry, Robert H. and Don Green, Perry's Chemical Engineers' Handbook. 6th edition, McGraw Hill Book Company, New York (1984).

[3] Hultgren, Ralph, Pramod D. Desai, Donald T. Hawkins, Molly Gleiser, Kenneth K. Kelley (University of California, Berkeley) and Donald D. Wagman (U.S. National Bureau of Standards), Selected Values of the Thermodynamic Properties of the Elements. American Society for Metals (1973).

[4] Barin, Ihsan, Ottmar Knacke and Oswald Kubaschewski, Thermochemical Properties of Inorganic Substances, supplement, Springer-Verlag Berlin Heidelberg New York (1977). 


\section{List of Tables}

Table 1. Amount of Sulfur Adsorbed (wt \% of adsorbent), Temperature was Maintained at $290 \pm 5^{\circ} \mathrm{C}$

Table 2. Amount of Sulfur Adsorbed (wt \% of adsorbent), Temperature was Maintained at $220 \pm 5^{\circ} \mathrm{C}$

\section{List of Figures}

Figure 1. Experimental Apparatus for Adsorption of Sulfur

Figure 2. Sulfur Vapor Pressure (atm) v.s. Temperature $\left({ }^{\circ} \mathrm{C}\right)$

Figure 3. The Amount of Sulfur Adsorbed on Various Kind of Adsorbents at $290 \pm 5^{\circ} \mathrm{C}$

Figure 4. New Experimental Apparatus for Adsorption of Sulfur

\section{DISCLAIMER}

This report was prepared as an account of work sponsored by an agency of the United States Government. Neither the United States Government nor any agency thereof, nor any of their employees, makes any warranty, express or implied, or assumes any legal liability or responsibility for the accuracy, completeness, or usefulness of any information, apparatus, product, or process disclosed, or represents that its use would not infringe privately owned rights. Reference herein to any specific commercial product, process, or service by trade name, trademark, manufacturer, or otherwise does not necessarily constitute or imply its endorsement, recommendation, or favoring by the United States Government or any agency thereof. The views and opinions of authors expressed herein do not necessarily state or reflect those of the United States Government or any agency thereof. 


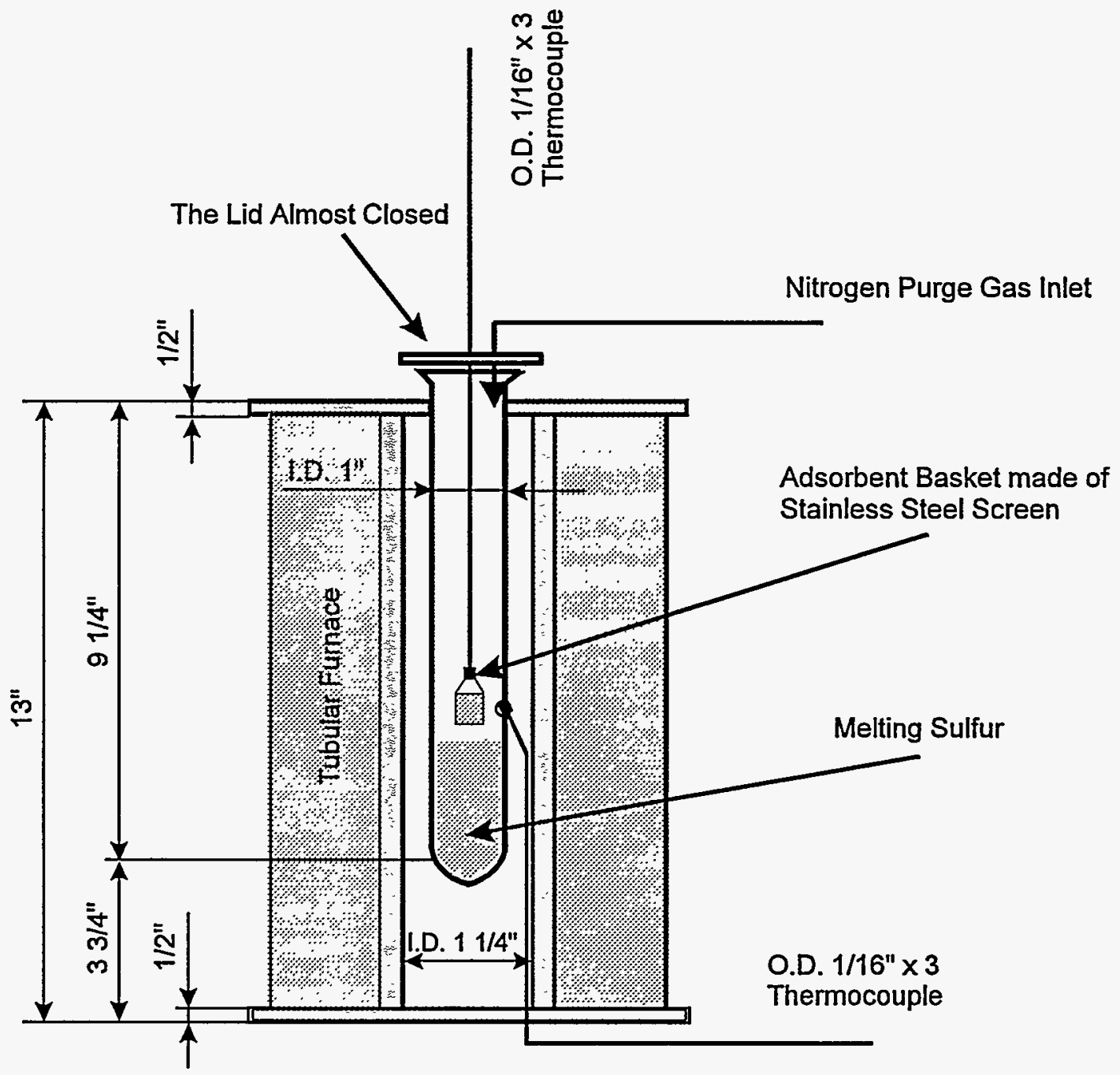

Figure 1. Experimental Apparatus for Adsorption of Sulfur 


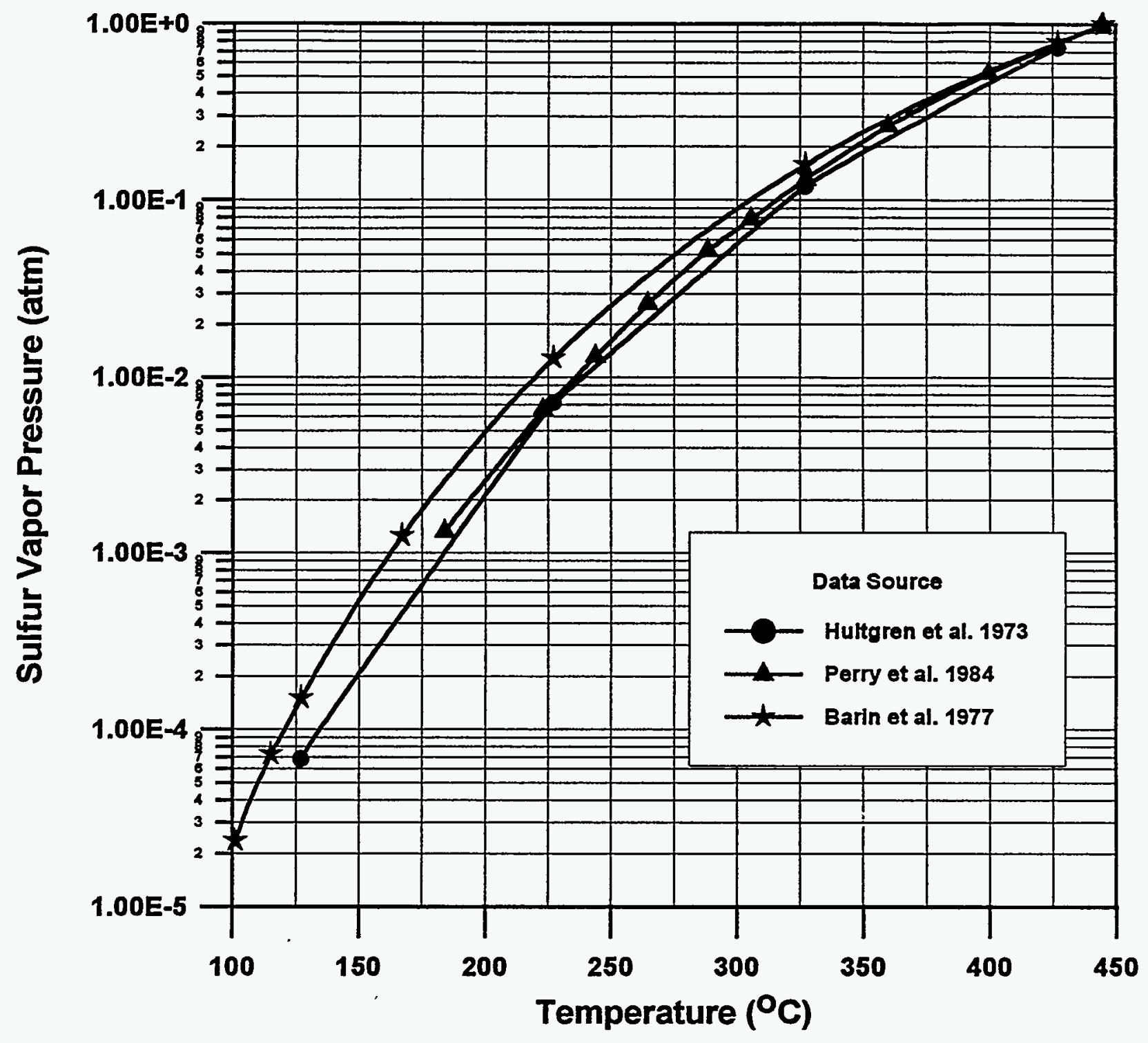

Figure 2. Sulfur Vapor Pressure (atm) v.s. Temperature $\left({ }^{\circ} \mathrm{C}\right)$ 


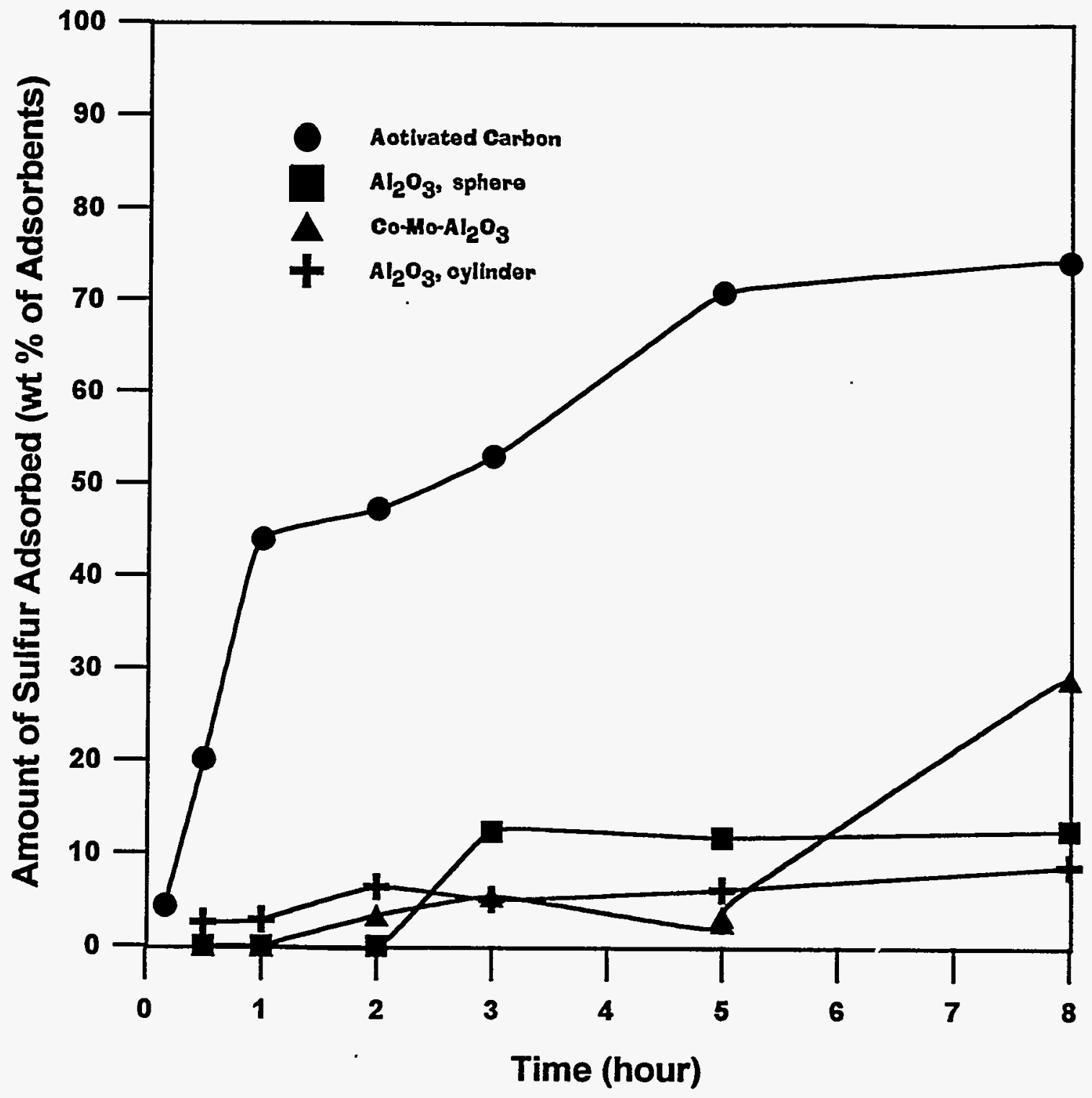

Figure 3. The Amount of Sulfur Adsorbed on Various Kind of Adsorbents at $290^{\circ} \mathrm{C}$ 


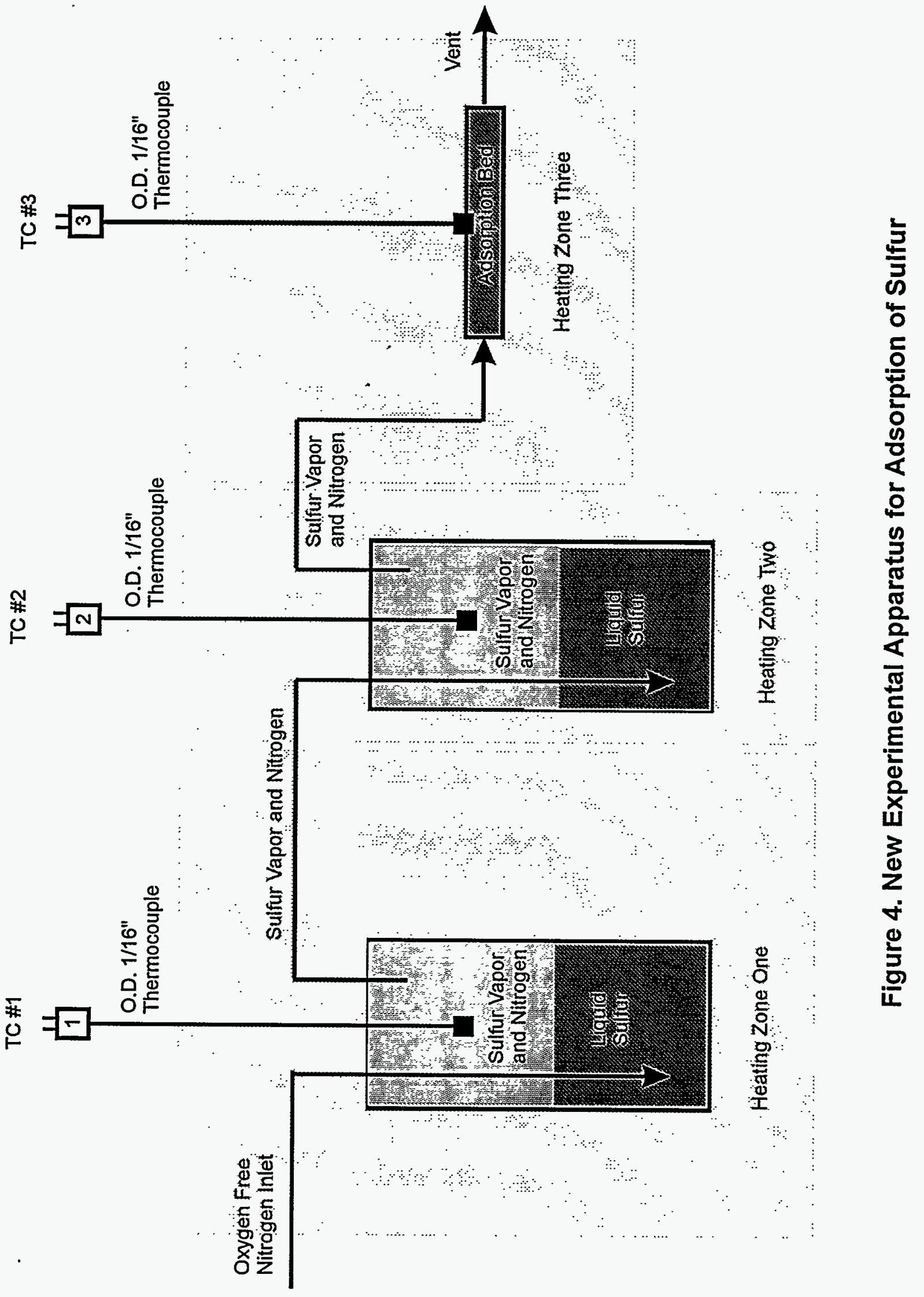

